\title{
Estimation of Population Fertility of a Dab Limanda herzensteini
}

\author{
Tsuyoshi KaWASAKI, ${ }^{* 1}$ Hajime SATo, ${ }^{* 2}$ and Ayako TAKECHI ${ }^{* 3}$
}

(Accepted May 29, 1985)

\begin{abstract}
In order to establish a method to estimate population fertility through the survey of commercially caught dab, research on maturation and spawning experiment through rearing fish were carried out. In the course of the former research age, growth by sexes, spawning season, regression of fecundity on body length, proportion of females participating in spawning, etc. were made clear. Through the latter experiment the pattern of maturation and oviposition and the relation between fecundity and fertility were disclosed. As a result, it was recognized that the type of maturation and oviposition of the dab is the bimode-split-batch spawning and the fecundity approximately equals the fertility. Considering the results together, a method to estimate the population fertility is proposed.
\end{abstract}

Limanda herzensteini is a dab distributed in shallow waters around northern Japan (northern Honshu, Hokkaido, and Kurile Islands). The aim of this paper is to study the method to estimate the population fertility of the dab through examining the relation between fecundity and fertility. As has been weil known, there are several patterns of maturation and oviposition in the marine teleosts and the relation between fecundity and fertility is not necessarily simple (KAWASAKI ${ }^{1)}$ ).

This study includes two experiments. One is an experiment about the maturation process of gonads of the dab, and TAKECHI had collected specimens and studied on this item and wrote Maturation and Fecundity. The other is a rearing experiment to establish actual fertility of the dab, which had been carried out by SATO who wrote Estimation of Fertility by Rearing Experiment.

\section{Definition of Terms}

\section{(after SATO and KAWASAKI ${ }^{2)}$ )}

Fecundity is the number of yolky oocytes in ovaries of a fish just prior to the first spawning in a reproductive cycle.

Fertility is the number of eggs actually produced in a reproductive cycle.

Pattern of maturation and oviposition is the developmental process of oocytes in ovaries of the adult female and the pattern of subsequent ovulation and oviposition in a reproductive cycle, which is expressed by the number of modes in size dis- tribution of yolky oocytes in ovaries just prior to the first spawning, the temporal change in size distribution of oocytes, and the number of times of spawning in a reproductive cycle.

\section{Maturation and Fecundity (By TAKECHI)}

\section{Materials and Methods}

Specimens were collected from landings from trawlers operating in Sendai Bay to the Haragama Fish Market between January and December, 1978. Samples were not available in July and August because of closed season.

\section{Differences in Growth due to Sex}

From age-specific body length*4 back-calculated by means of year rings formed on otoliths, growth equations were obtained.

$$
\begin{aligned}
& \text { ठ: } L_{t}=20.7\left(1-\mathrm{e}^{-0.587(t-0.220)}\right) \\
& \text { \&: } L_{t}=42.9\left(1-\mathrm{e}^{-0.228(t-0.288)}\right)
\end{aligned}
$$

$L_{t}$ is the length in $\mathrm{cm}$ when $t$-th ring is formed. As seen in Fig. 1, the female tends to grow faster than the male, after their third year of life. Although the asymptotic length of female and male is $43 \mathrm{~cm}$ and $21 \mathrm{~cm}$ respectively in the equations, the maximum length in samples available was $33 \mathrm{~cm}$ for female and $22 \mathrm{~cm}$ for male, showing that the female does not reach the asymptotic length.

\section{Seasonal Change in Maturation}

To establish the spawning season of the dab, seasonal change in $\mathrm{GSI}^{* 5}$ (Fig. 2) and that in lengthspecific frequency of ripe fish (Fig. 3) are shown.

*1 Faculty of Agriculture, Tohoku University, Sendai 980, Japan (川崎 健：東北大学费学部).

*2 Wakkanai Fisheries Experimental Station, Wakkanai 097, Japan (佐藤 一; 稚内水産試蹑場).

*3 Iwate Prefectural Fisheries Experimental Station, Kamaishi 026, Japan (武智文子：岩手其水産試験場).

*4 Body length is the distance from tip of the snout to hind margin of the hypural bone of the tail.

*5 Gonadosomatic Index, gonad weight as a percentage of body weight. 


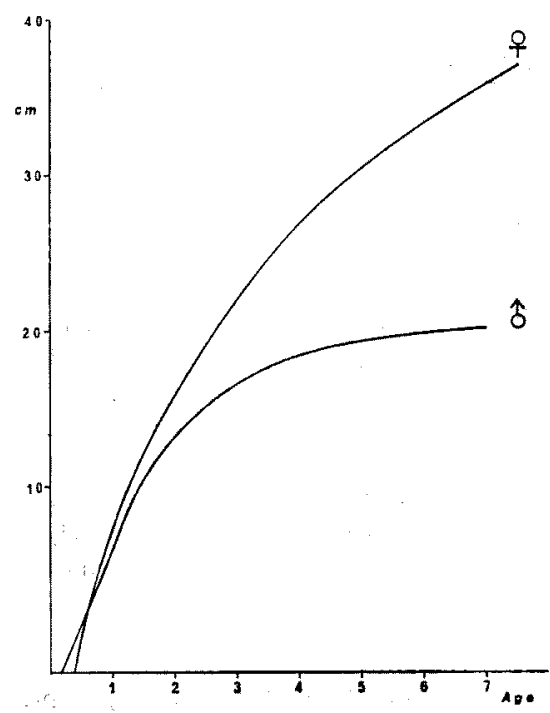

Fig. 1. Growth curves for different sexes by von Bertalanffy's method.

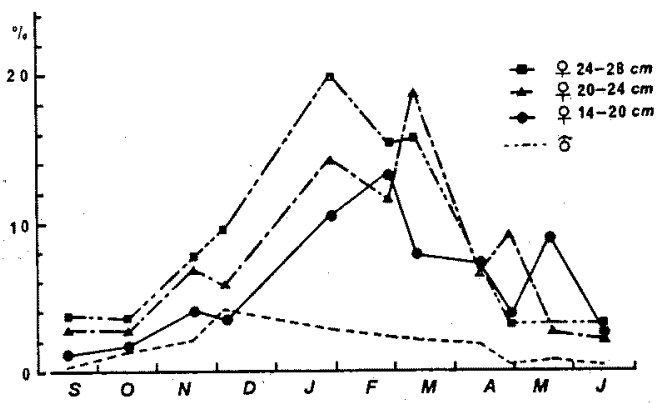

Fig. 2. Seasonal change in GSI by different length range.

Ripe fish is categorized by (1) that fish seems to have spent its eggs and (2) that its GSI exceeds $10 \%$. The authors take it that fish with GSI of $10 \%$ and more would raise eggs, depending on $\mathrm{WADA}^{3)}$ who says that most fish over 2 in GI (gonad index $=10^{3} \times$ gonad weight(g)/body length $(\mathrm{cm})^{3}$. 2 in GI roughly corresponds to $10 \%$ in GSI) had eggs which had developed beyond the secondary yolk phase in their ovaries and also depending on YAMAMOTO ${ }^{4)}$ who points out that no ovaries of the preadult flounder Liopsetta obscura ever advanced beyond the primary yolk phase, although they revealed seasonal variation.

The change in frequency of ripe females with time shows that most fish over $20 \mathrm{~cm}$ in length had spawned and about half of those $14 \mathrm{~cm}$ long became ripe. Examining Figs. 1 and 3 together shows that more than half of the three- and four-
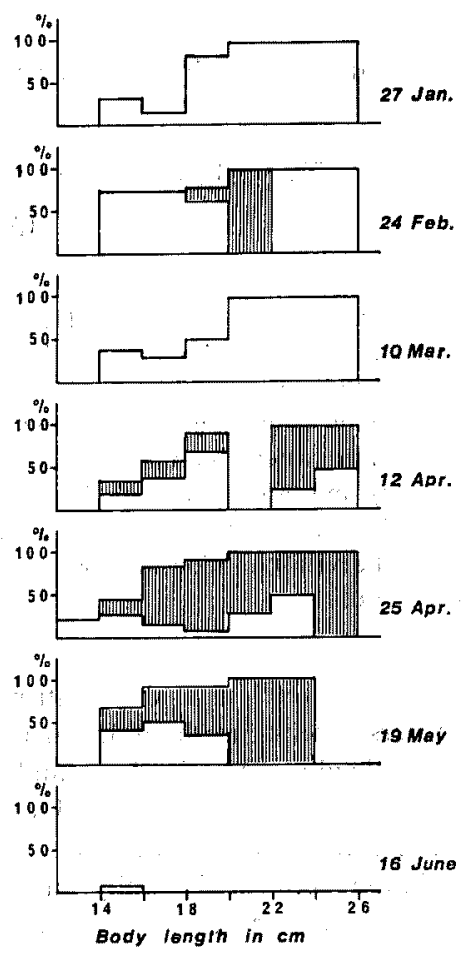

Fig. 3. Change in length-specific frequency of ripe fish with GSI higher than $2 \%$ (blank part) and that of spent fish (shaded part).

year-old fish over $20 \mathrm{~cm}$ had already spawned by mid-April, subsequently two-year-olds between 14 and $20 \mathrm{~cm}$ and slowly-grown three- and fouryear-old fish had become ripe, and by mid-May over half of ripe two-year-olds produced their eggs.

Seasonal change in male GSI shows that it increased sharply in November and December. Histological structure of a testis in December showed the formation of spermatozoa, suggesting the ability of discharge. GSI of the male decreased slowly between December and April.

GSI of the female $20-28 \mathrm{~cm}$ long remained at a high level of 10-20\% from January to March. GSI of the fish of $24-28 \mathrm{~cm}$ and that of $20-24 \mathrm{~cm}$ peaked in late January and February and in late February and March, respectively. On the contrary, GSI of the male $14-20 \mathrm{~cm}$ long changed trapezoidally, staying around $10 \%$ between January and May.

We can sum up as follows: the dab is a protandron and large females of $20-30 \mathrm{~cm}$, which are mainly composed of three and four years of age, are major spawners. In April and May of the latter half of the spawning season, part of two- 


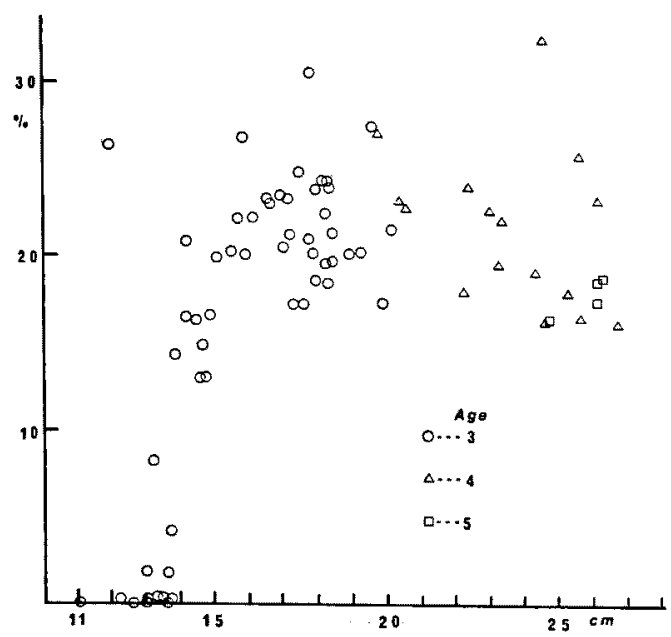

Fig. 4. Regression of maximum GSI on body length for different ages between 27 January and 19 May in 1978.

year-olds and smaller fish of three and four years of age replace the predecessor.

\section{Biological Minimum Size}

From the regression of maximum GSI on length, the biological minimum size would be $14 \mathrm{~cm}$ for the female (Fig. 4). A smallest ripe female of $160 \mathrm{~mm}$ was sampled by the Tohoku Regional Fisheries Research Laboratorys) on the Pacific coast off northern Honshu and one of $123 \mathrm{~mm}$ was collected by WADA $^{\text {s) }}$ in the Sea of Japan off
Niigata.

The biological minimum size for male was estimated to be $8 \mathrm{~cm}$ from the histological structure in December.

\section{Pattern of Maturation and Oviposition}

Fig. 5 shows the size distribution of oocyte with change in GSI. The distribution does not include nonyolky oocytes under $0.2 \mathrm{~mm}$ in diameter. An oocyte group entered upon the growth phase (vitellogenic growth) at 2.5 in GSI. The oocyte group had grown gradually and its mode reached about $0.5 \mathrm{~mm}$ at $22.2 \mathrm{in}$ GSI. Part of the oocytes seem to have started maturation division when GSI rose to 23.4 (maturation phase) and they got larger and became transparent due to hydration. At a stage of 26.9 in GSI another small oocyte group $0.7-1.0 \mathrm{~mm}$ across appeared and was ready to release, although the original one of $0.5 \mathrm{~mm}$ mode remained unchanged. Subsequently the original oocyte group seems to have been split several times into ripe groups, which would have been eventually spent, while GSI declined steadily. When GSI decreased to 4.3 , final maturing oocyte group shifted from the original one, which consequently disappeared.

$W_{A D A}{ }^{3)}$ got similar result for dabs off Niigata. $\mathrm{He}$ reasoned that after near-ripe oocytes with the larger mode had been released following oocyte groups started to mature from the smaller oocyte group and were released in several batches.

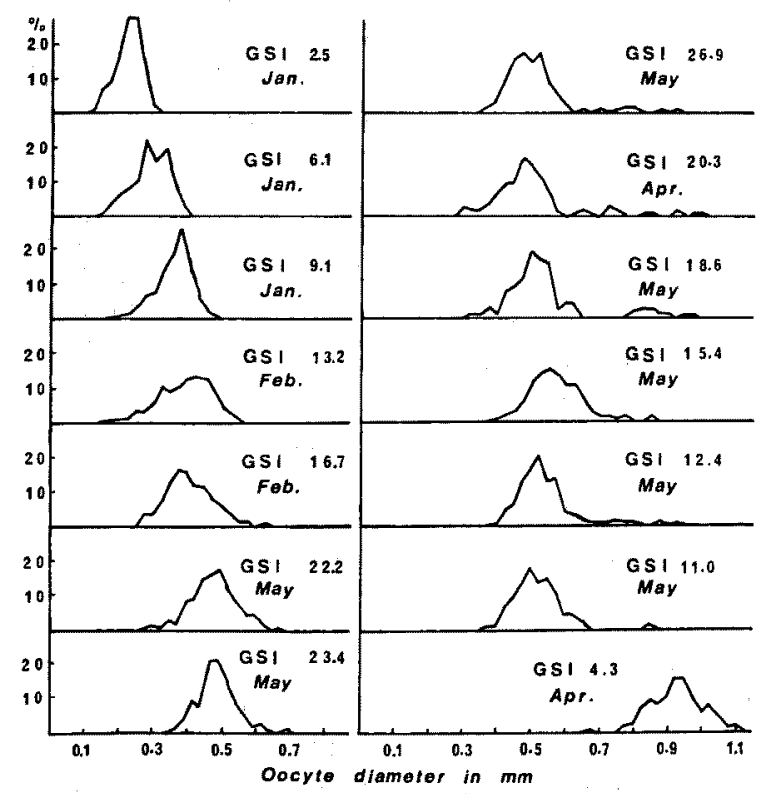

Fig. 5. Progress of distribution of oocyte diameter with maturation in 1978. 


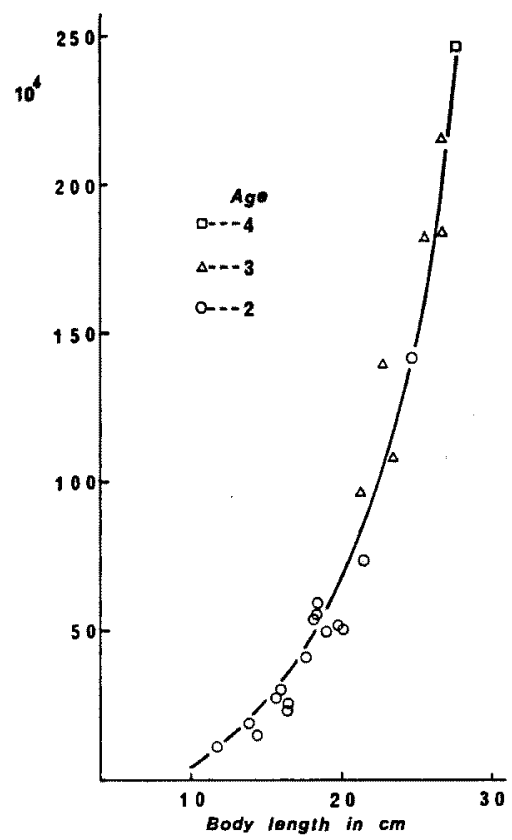

Fig. 6. Regression of fecundity on body length.

From above results, the pattern of maturation and oviposition in the dab would be considered the bimode-split-batch spawning.

\section{Fecundity}

The regression of fecundity on body length is shown in Fig. 6. The regression equation runs as follows:

$$
\text { Fecundity }=9.3 \times \text { Body Length }(\mathrm{cm})^{3.7}
$$

\section{Estimation of Fertility through} Rearing Experiment (By SATO)

\section{Materials and Methods}

A number of live dabs which had been landed at the Haragama Fish Market on the Pacific coast of Fukushima Prefecture on 25 January 1982 were carried to the Matsushima Aquarium, Miyagi. After having been acclimated in a concrete trough, one female and two males were transferred to an observation trough of acrylic fiber, some $400 \mathrm{l}$ in capacity. Sea water in the trough was forced to circulate through filtering apparatus and at the same time fresh sea water which had been pumped from Matsushima Bay and filtered was poured into the trough to hold water temperature at the level close to that in Sendai Bay. The bottom of trough was covered with sand of few centimeters thick. The fish were fed with sandeel at a suitable level. To collect released eggs the
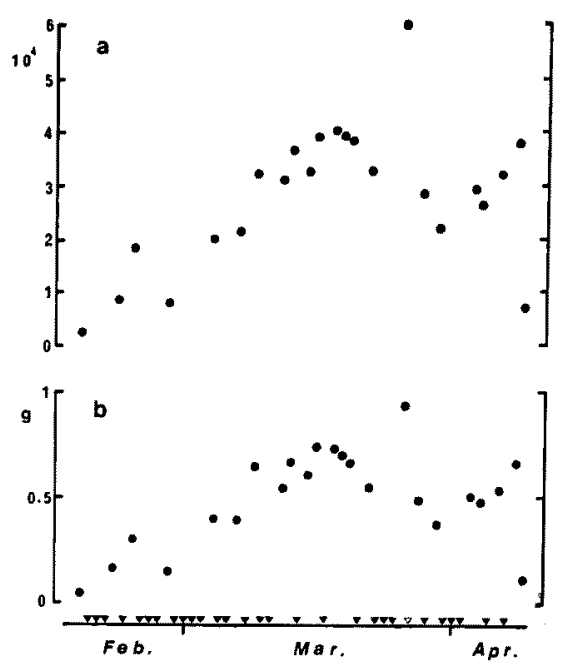

Fig. 7. Daily change in number (a) and total dried weight (b) of eggs produced by a reared dab of $20.9 \mathrm{~cm}$ in 1982.

$\nabla$-.. day when eggs were not produced.

$\nabla$-.. day when observation was not made.

trough was equipped with a net trap which overflowing sea water descended through. The trap was checked once a day and eggs were sampled if they were present. Dab eggs sampled were fixed with $10 \%$ formalin-sea-water solution on the spot for preservation and subsequently they were counted and weighed. All eggs were counted when their number seemed to be under about 20,000 at a glance and otherwise the egg number were estimated indirectly by the volumetric method with a settling tube. After counting eggs were dried at $60^{\circ} \mathrm{C}$ for more than $24 \mathrm{~h}$ before weighing them to the nearest $0.1 \mathrm{mg}$. After rearing experiment the fish was killed to measure its body length, to weigh body and ovaries, and to take out otoliths for age determination. The ovaries had been fixed in formalin-sea-water solution, part of which were used for histological study.

\section{Results}

Final length and weight of the female when the rearing experiment terminated on 25 April were $209 \mathrm{~mm}$ and $136 \mathrm{~g}$ and the fish turned out to be three years old from its otolith.

Oviposition started on 17 February and eggs had been collected from the trap net twenty three times by 9 April. The water temperature rose from $6.2^{\circ} \mathrm{C}$ to $12^{\circ} \mathrm{C}$ during the experiment. Spawning interval had been 2-5 days until early March, followed by one of 1-3 days, and the average was 1.9 days. Figs. $7 \mathrm{a}$ and $7 \mathrm{~b}$ show the temporal 


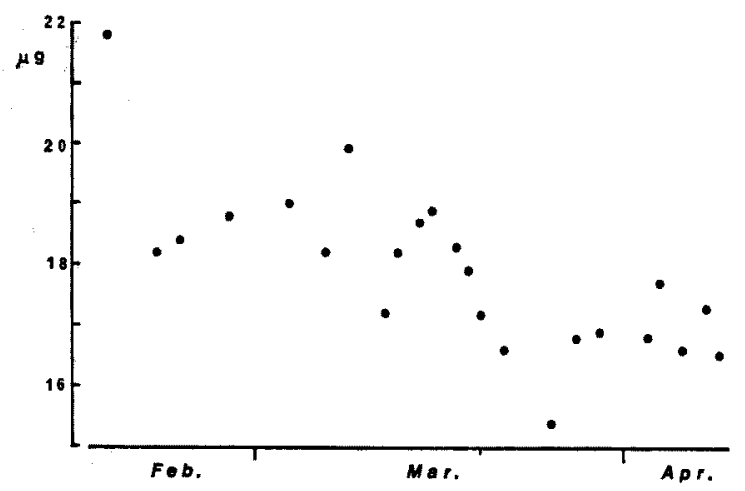

Fig. 8. Daily change in average dried weight of an egg produced by the dab.

change in egg number of every collection and that in the dried weight respectively. The former had increased gradually from about 2,000 to about 20,000 and remained at somewhat constant level of 20,000 to 60,000 . Egg weight changed in the same way as the egg number.

Oviposition of the dab until early March seems to have been unusual in that the egg number produced at a time was smaller, and interspawning time was longer, perhaps owing to insufficient acclimation of the fish to the trough.

The average egg number laid between 7 th and 22nd spawning was 32,800 . According to $\mathrm{W}_{\mathrm{ADA}}$, ${ }^{3)}$ who studied the relation between the number of transparent (ripe) eggs and body length of the dab in the Japan Sea side, the number of transparent eggs of fish over $200 \mathrm{~mm}$ in length was 15,000 to 40,000 , being comparable to the above figure. This means that a group of mature eggs corresponds to a batch to be produced.

Histological section of the ovary showed not only eggs left but oocytes developing beyond the nonyolky stage.

Fig. 8 represents the temporal change in average egg weight, showing that the size of eggs produced became smaller with time. This fact agreed with the rearing consequences of other split spawners or serial spawners (for example, see HISLOP ${ }^{()}$), which are common for them.

\section{Relation between Fecundity and Fertility and Estimation of Population Fertility}

From the equation (3), a dab $209 \mathrm{~mm}$ long is expected to keep 710,000 ovarian oocytes, which are close to the actual number spawned by the reared fish, 610,900. Considering the results integrally, in the case of the dab the fecundity is almost identical with the fertility and no oocytes start

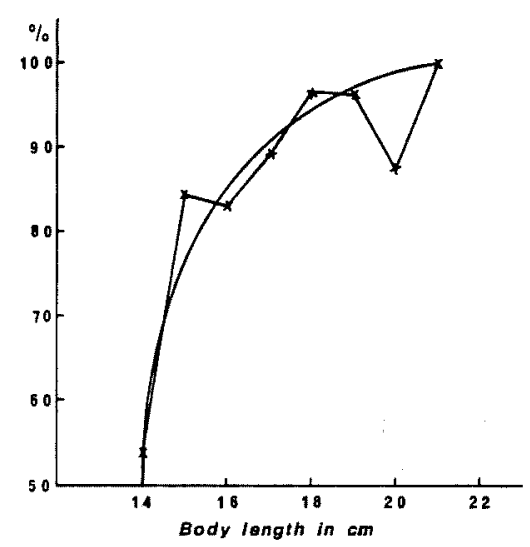

Fig. 9. Length-specific proportion of females. Crosses denote original observation and a curve is arbitrary.

to grow from the immature oocytes once the reservoir oocytes have been formed. Ripe oocytes split from the reservoir are laid at a time and splitting occurs intermittently at few days' interval and all of the reservoir oocytes will be spent in the end.

Next, we examine the method for estimating population fertility, PF. To estimate this value, four kinds of data are essential: length-specific number of fish, $N_{l}$, fecundity at $l \mathrm{~cm}, F_{l}$, proportion of females at $l \mathrm{~cm}, I_{l}$, and that of spent or maturing females among all females, $M_{l}$.

If above observations are available, PF is expressed as follows:

$$
\mathrm{PF}=\int_{0}^{\infty} N_{l} F_{l} I_{l} M_{l} \mathrm{~d} l
$$

As numerical calculation, the formula

$$
\mathrm{PF}=\sum N_{l} \cdot F_{l} \cdot I_{l} \cdot M_{l}
$$

is obtained.

$F_{l}$ will be calculated from the equation (3). As 


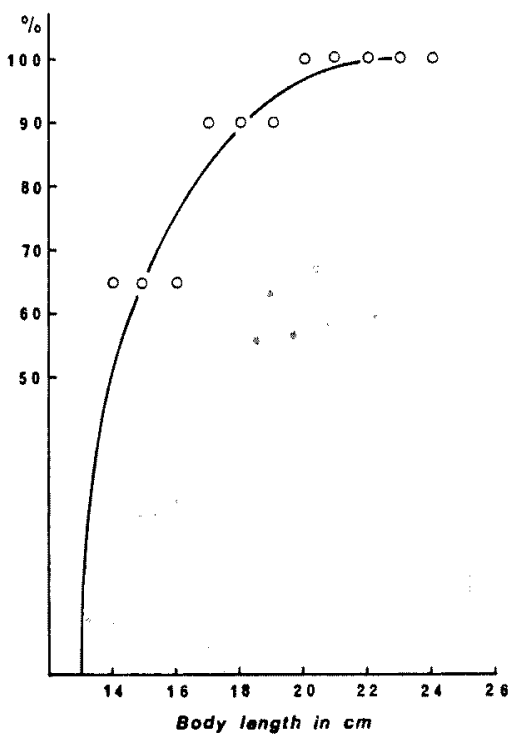

Fig. 10. Regression of proportion of spawning females on body length. Open circles denote original observation on 19 May, 1978 in Fig. 3 and a curve is arbitrary.

for $I_{l}$, we have Fig. 9 based on the survey at Haragama by TAKECHI. Beyond $14 \mathrm{~cm}$ in body length, under which the sexual difference in length is not found and sex ratio remains at 0.5 over the whole range, the growth rate of the female start exceeding that of the male sharply and all of the fish over $21 \mathrm{~cm}$ turn out to be females. An arbitrary curve of the change in proportion of females between 14 and $21 \mathrm{~cm}, I_{l}$, is drawn in Fig. 9 which enables us to read the length-specific proportion.
In Fig. 3 the change in proportion of maturing females, $M_{l}$, with time is shown. Since a sample taken on 19th May in the figure is considered one close to the terminal stage of spawning, we made a regression curve of the proportion of spawning females on body length in Fig. 10 depending on data of the sample, to read the length-specific expectation of the proportion, $M_{\imath}$.

\section{Acknowledgements}

We must express our heartfelt thanks to the members of the following Fisheries Cooperative Associations for their help in sampling: Haragama, Onahama, and Yotsukura, Fukushima, and Onagawa, Miyagi. Our appreciation is due to the staffs of the Matsushima Aquarium, Miyagi, especially Mr. J. JINGU, and also those of the Onagawa Fisheries Experimental Laboratory, Tohoku University, in particular Associate Professor K. SeKuno and Mr. K. ABE, for their help in rearing experiment and sampling.

\section{References}

1) T. Kawasaki: Ukiuo-Shigen (Pelagic Fish Resources), Koseisha-Koseikaku, Tokyo, 1982, pp. 99-160.

2) H. Sato and T. Kawasaki: Tohoku J. Agr, Res,, 34, 19-26 (1983).

3) K. WaDA: Bull. Japan Sea Reg. Fish. Lab., 11, 68-77 (1970).

4) K. YамAMoto: Bull. Hokkaido Reg. Fish. Res. Lab., 11, 68-77 (1954).

5) Tohoku Regional Fisheries Research Laboratory: Tohokusuiken-Sosho, 5, 1-9 (1952).

6) J. R. G. Hrslor: J. du Cons., 36, 119-127 (1975). 